\title{
A study of positive and negative role of online advertisements in the growth of modern business
}

\author{
Niyas Ahamed $\mathbf{M}^{1, *}$, Chilar Mohamed $\mathbf{P}^{2}$ \\ ${ }^{\mathbf{1}}$ Assistant Professor, ${ }^{2}$ Associate Professor (Research Guide), Dept. of Commerce, Khadir Mohideen College, Adirampattinam, Tamil \\ Nadu, India
}

*Corresponding Author: Niyas Ahamed M

Email: rvmitr01@gmail.com

\begin{abstract}
The optimistic role played by online advertisements in the marketplace progression has been fundamentally ignored by academic economists. It is only just, since the modern economic revolution, that economists have realize the benefits of online advertising and have joined the research agenda developed by researchers in marketing and other business fields. The present survey details the literature that examines the role played by online advertising in lowering the 'full price' to consumers which allows consumers to make the most of utility and allows the producers/retailers to maximize profits. An online advertisement carries a number of farm duties, advertising report to the community so with the intention of they can be mindful of products and build informed option amongst diverse products or brands. Advertising too settlement businesses in supporting them to put up for sale their products. The studies determine the usefulness of on an online advertisement and also examine the socio-economic development at Tamilnadu, India.
\end{abstract}

Keywords: Advertisements, URL, Display Ads, Web traffic and Post roll.

\section{Introduction}

Online advertisement also called digital marketing or Internet \& web advertising is an appearance of selling and marketing. Its uses the Internet to distribute promotional selling communication to customers. Consumers sight of online advertising as a superfluous interruption with a small number of reimbursements and contain ever more turned to ad blocking for a diversity of rationale. The software is used to perform the purchase; it is well-known as programmatic advertising.

It include e-mail marketing, search engine marketing and social media marketing, a lot of types of display advertising (together with web banner ads), and teleadvertising. Similar to further advertising media, online advertising commonly involve both a publisher, who integrates advertisement keen on its online contented, and an advocate, who provides the advertisements to be display on the publisher's comfortable. Other latent contributors comprise advertising agencies who assist create and position the ad facsimile, an ad server which technically conveys the ad and pathway figures, and advertising associates who do self-governing promotional employment for the supporters.

A lot of frequent online advertising practices are contentious and gradually more subject to guidelines. Online ad revenues may not sufficiently substitute other publishers' income streams. In the speedily increasing and ever-shifting digital age in which we be alive, the function of Internet marketing in recent marketing is no longer a negligible one. Internet marketing is a crucial part of the achievement of any association. Beginning IT sustain to lead creation to sales, internet marketing is advantageous to nearly each piece of the company.

Internet marketing, which also goes away by the given name of online marketing, digital, web and e-marketing, etc., is defined as the process of promote brands, products, or services, in excess of the Internet. It includes several promotional dealings that are complete via the Web or wireless media, together with email advertising, blogging, SEO, and social media. The worldwide attain of the Internet has completed it potential for businesses to effortlessly arrive at more than hundreds of new clientele and has redefined interaction among businesses to businesses and businesses to consumers. All the way through the Internet, marketers from organization of every one sizes are at the present intellectual to contribute to brands, products, and services on a universal scale and can perform so all the point in time. All the way through web, blogs, and media platforms, customers are talented to find and admittance information concerning and from an association $24 * 7$, from somewhere they are in. Due to the most important role of Internet marketing in contemporary marketing, organizations cannot meet the expense of to overlook marketing online. Because the huge preponderance of citizens use up a important amount of instance online, whether they are at exertion or residence on a laptop and desktop computer, or waiting on the airfield on a Smartphone or digital piece of equipment, advertising through the Internet provider organizations a more effectual approach to encourage them-selves. It also provides a additional resourceful way for the reason that it does not engage the expenses that habitually come up to with established marketing. Expenses that often comprise printing promotional material, distribution out promotional mailers, and paying for announcement advertising.

\section{Review of Literature}

Kanso and Nelson (2004) examine the synergies of online and magazine advertising. Their content analysis reveals that there is a lack of integration between print ads and web sites and that print ads only listed the URLs in small letters and without any specific reference to the specialized features of the website. Ilfeld and Winter (2002) 
inspect the recital of the persuasive hierarchy model, the low-involvement hierarchy, and the no-involvement model in explaining web site traffic. They find that the low involvement hierarchy best models the process through which advertising affects awareness, site visitation, and brand equity on the internet. Specifically, offline advertising appears to increase site visitation through its significant influence on consumer awareness, while online advertising directly leads to increased website traffic. The most significant factor in building awareness is the word-ofmouth generated from lagged visits.

The bulk of online advertising research views online advertising as an alternative to offline media advertising. Synergies of online advertising with other new media and traditional media determine the success of an integrated marketing communication campaign (Schumann, Artis and Rivera, 2001). Only four empirical studies published in advertising journals directly examine the synergies between online and offline media. Two of the four studies examine the synergies between TV and Online. Ha (2003) compares the online advertising strategies of web portal sites (online media) and web sites of TV networks using content analysis and finds that web portal sites are much more aggressive in developing online advertising as a source of revenue than TV networks.

The observational study describe by Novak et al. (2003) initiate that stream state occur in together goal-directed and undirected browsing, still although when people are goal bound for they are additional probable to bring to mind concrete situations where run occurred to them (i.e., their discernment of run state improve).

\section{Objectives of the Study}

1. To study of the role of online advertisements in the growth of modern business in Tamilnadu state.

2. To measure the effectiveness online advertisements in the growth of modern business

3. To analyze the impact of economic and social role online advertisements in modern business environment

\section{Research Design}

The information is composed from a variety of sources like as newspapers, magazines and websites. Data was collected from its inception till 31.09.2018. For presentation, the table is used and for analysis percentage method used.

\section{The Effectiveness of Online Advertisements in Modern Business}

When people communicate about advertising, eight out of ten they're approximately definitely referring to online advertisement. Online advertising has long-established to be enormously profitable in cooperation for small and large business. Reports assigned that just about ninety four percentages of Google's profits comes as of online advertisement. The regular being is portion over 1,700 poster ads apiece month but only partially of them are always view. The businesses have sharpened their tools and are sift the Ads that are not creature viewed. Through liability so, businesses have administer to obtain improved brand raise by twenty nine percentage. Toward be familiar with other; create certain out the succeeding information striking on "efficiency of Online Advertising- figures and trend at Tamil Nadu".

Table 1

\begin{tabular}{|l|c|}
\hline Category & Percentage in-Target \\
\hline Computer /Technology & $64 \%$ \\
\hline Telecom & $60 \%$ \\
\hline Travel & $53 \%$ \\
\hline Media/Entertainment & $52 \%$ \\
\hline Auto & $50 \%$ \\
\hline Finance & $46 \%$ \\
\hline Health/Wellness & $42 \%$ \\
\hline Retail & $42 \%$ \\
\hline
\end{tabular}

Table 2: Percentage in-target by age and sex

\begin{tabular}{|l|c|c|c|}
\hline \multicolumn{3}{|c|}{ Male } & \multicolumn{2}{c|}{ Female } \\
\hline Age Group & \% & Age Group & \% \\
\hline $20-34$ & $42 \%$ & $20-34$ & $35 \%$ \\
\hline $20-49$ & $45 \%$ & $20-49$ & $43 \%$ \\
\hline $22-35$ & $33 \%$ & $26-49$ & $37 \%$ \\
\hline $26-35$ & $33 \%$ & $26-54$ & $36 \%$ \\
\hline $26-49$ & $32 \%$ & $36-64$ & $31 \%$ \\
\hline $26-54$ & $42 \%$ & & \\
\hline
\end{tabular}

On the whole average apparent rate is $46 \%$

Table 3

\begin{tabular}{|l|c|}
\hline \multicolumn{1}{|c|}{ Category } & Average In-view Rate \\
\hline Travel & $49 \%$ \\
\hline Health/Wellness & $48 \%$ \\
\hline Computer/Technology & $47 \%$ \\
\hline CPG & $47 \%$ \\
\hline Media/Entertainment & $46 \%$ \\
\hline Retail & $45 \%$ \\
\hline Auto & $40 \%$ \\
\hline Finance & $40 \%$ \\
\hline Telecom & $36 \%$ \\
\hline
\end{tabular}

Table 4: How people act in response to online ads

\begin{tabular}{|l|c|}
\hline \multicolumn{1}{|c|}{ Response Type } & Percentage \\
\hline by means of click on the Ads & 31 \\
\hline $\begin{array}{l}\text { by means of probing for product, } \\
\text { company or brand }\end{array}$ & 27 \\
\hline $\begin{array}{l}\text { by means of typing company web } \\
\text { address in their browser }\end{array}$ & 21 \\
\hline $\begin{array}{l}\text { Researching more communication about } \\
\text { a product }\end{array}$ & 9 \\
\hline
\end{tabular}

1. On average, $4 \%$ of Ad impersonations were delivering outer surface the intentional topography.

2. Seventy two percentages of campaigns had at minimum amount some impersonations that were convey neighboring to untoward content. 
3. Non-human traffic, collectively with fraud, range from 4 to $11 \%$.

4. More than $70 \%$ of marketers are ineffective to target customers between behavioral facts.

5. Almost $60 \%$ of digital video advertisers are underprovided in tools and judicious facts to settle on digital video campaigns.

6. Almost $75 \%$ of respondents listed vision ability and brand pick up as the metrics that would most influence digital video advertising strategy.

7. Greater than $80 \%$ motionless at present rely on impersonation and clicks to find out digital video Ads

8. Mid-roll video ads situated in the central point of a video had the uppermost finishing point rate of $97 \%$

9. Pre-roll Ads located in the commencement and post-roll ads positioned in the end yield significantly smaller accomplishment rates (74 and 45 percentages respectively).

10. 25-second Ads had the smallest amount concluding point rate of $62 \%$ in our information set, with 15 second and 30-second Ads completion at higher rates of 84 and 90 percentages respectively.

\section{Role and Impact of Online Advertising in Economic and Social Development}

In Indian state of dealings Online advertising has a extremely great manipulation in the mass media market point as it pays the majority of the bills and thus theaters a main role in influential the content and progression of the mass media in India.

Online Advertising as well as plays a momentous role in the popular Indian culture since it shapes and reflect our life styles. It is in general the first to imitate social trend. The online advertisement of Amul products.

Online Advertising encourages a privileged excellence of goods through the ability of the consumer to recognize a particular producer and thus create a need for that manufacturer to sustain the excellence. Advertising also gives business the aptitude to roll-out new products immediate enough to compensate the costs of generate such products.

Online Advertising protects industry from government and surprising control as it democratizes in development to customers as to what goods and services are obtainable.

Online advertising acting two succeeding extensive roles in the socio-economic scenery of a country:

1. Economic roles

2. Social roles

\section{Economic Impact of Online Advertisement}

Online Advertising executes an economic function for an advertiser, influences economic choice of the audience and is a necessary part of the entire economic system.

Online Advertising excite demand, educate customer about new product, norms, policies, programmers services, methods and organization, add to competition and get improved standard of everyday life by serving to bring new product to the purchaser.
Online Advertising boost the economy by helping to introduce new products faster and more efficiently to consumer by supporting to accomplish the economies of scale more rapidly and by helping to abolish the domination of the products and services.

\section{Social impact of Online Advertisement}

At social level advertising acting upon, obtain from and contribute to the social steadiness of a nation. A choice of social changes is carry about or help by marketing. Mature instruction, family plan and pulsation polio society are the example of little victorious social advertising operation. It creates role models who can create societal transforms.

Online Advertising is efficient source of information for product and service quality, new material, merchandise, new technology and cost. It diminishes allocation expenses, provides assurance in competition and increase product and service quality through brand uniqueness.

It ropes of mass media to safeguard the independence from government, political party and other special curiosity groups.

\section{Negative impact of Online Advertising in the Socio-} culture environment

Abhorrent and in Awful Flavor: Some critics sense that advertising is abhorrent for the reason that the imaginative endeavor in the wake of it is not in good quality of flavor. Persistent, recurring, illusory, disagreeable and disappointing are some of their distasteful facial appearances.

Intense Panic Appeal: The panic appeal in advertising creates uneasiness that is made-up to be subsidizing by an obtainable product and services. Such appeals may generate poignant disturbances in a number of audiences in target customers. Products comparable to equality cream products, insurance, banking and toothpaste all tries to fit into place in recreation with the panic factors.

Intrusiveness of Products: An Online advertisement operation drives with imitation from a time period of effectiveness to appreciation, to a time of enragement.

Manipulation: An Online advertisement have the raw supremacy to control consumers. A lot of companies have the competence to get hold of large numbers of advertisement disclosure, which is not good for vigorous opposition in the market.

Special Effects on Values and Standard of Living: Online Advertising receives extensive disclosure as it is dispersed all the way through mass media. It has a belongings on what populace buy and thus on their performance. It is a persuasive motor vehicle which has fender-bender on the principles, morale's and life-style of the social order. The collide of advertising has its unresponsive as well as optimistic side.

The Relationship of Advertising to Acquisitiveness: The Online Advertisement creates or fosters acquisitiveness. Acquisitiveness is defined as the inclination to give undue implication to material interests. People acquire high-end lavishness products for community standing. It reflects broken up values, norms and attitude that are created by more noteworthy sociological forces. 
Online advertisement acting role of creating harmful typecast of women and racial minorities. Contribution of advertising in promotes injurious products - The hurtful products are promoted throughout surrogate advertising in the social order

\section{Conclusion}

In today is tricky market condition, online advertisement has grown to be an imperative constituent of the modern business. Moreover, online advertisement plays an influential advantageous role and responsibilities in the economic progress of a nation. In the deviating, they can frequently play an unconstructive responsibility in gentleness the sentiment of an entity or the civilization. Hence, it is imperative that online advertising specialized examine high moral principles in observe to forthrightness, human being distinction and social ranch duties and responsibilities of modern business.

\section{Conflict of Interest: None.}

\section{References}

1. Schumann, David W., Andy Artis and Rachel Rivera (2001), "The Future of Interactive Advertising Viewed Through an IMC Lens," Journal of Interactive Advertising, spring.

2. https://www.researchgate.net/publication/241729514_Online_ Advertising_Research_in_Advertising_Journals_A_Review
3. Bayles, M. J. (2000). Just how blind are we to advertising banners on the web. Usability News, 2(2), 520-541. http://www.surl.org/usabilitynews/22/banners.asp Bayles, M. J. (2002). Designing online banner advertisements: Should we animate? In CHI '02: Proceedings of the SIGCHI Conference on Human Factors in Computing Systems (pp. 363-366). New York: ACM.

4. Hartmann, J., Sutcliffe, A., \& De Angeli, A. Towards a theory of user judgment of aesthetics and user interface quality. ACM Transactions on Computer-Human Interaction. 2008;15(4):130.

5. http://www.indianmediastudies.com/role-of-advertising-ineconomic-and-social-development/

6. https://studypoints.blogspot.com/2011/06/what-is-role-ofadvertising-in-present_9703.html

7. https://www.invespcro.com/blog/effectiveness-onlineadvertising/

8. http://www.ijarcsms.com/docs/paper/volume3/issue10/V3I100047.pdF

9. https://www.business2community.com/digital-marketing/roleattribution-online-advertising-01691350

How to cite this article: Niyas A. M, Chilar M. P. A study of positive and negative role of online advertisements in the growth of modern business. $\mathbf{J}$ Manag Res Anal. 2018;5(4):397-400. 